\title{
Against the odds? Educational attainment and labour market position of the second generation minority ethnic members in the UK
}

DOI:

10.1177/1468796818777546

\section{Document Version}

Accepted author manuscript

Link to publication record in Manchester Research Explorer

Citation for published version (APA):

$\mathrm{Li}$, Y. (2018). Against the odds? Educational attainment and labour market position of the second generation minority ethnic members in the UK. Ethnicities, 1-25. https://doi.org/10.1177/1468796818777546

\section{Published in:}

Ethnicities

\section{Citing this paper}

Please note that where the full-text provided on Manchester Research Explorer is the Author Accepted Manuscript or Proof version this may differ from the final Published version. If citing, it is advised that you check and use the publisher's definitive version.

\section{General rights}

Copyright and moral rights for the publications made accessible in the Research Explorer are retained by the authors and/or other copyright owners and it is a condition of accessing publications that users recognise and abide by the legal requirements associated with these rights.

\section{Takedown policy}

If you believe that this document breaches copyright please refer to the University of Manchester's Takedown Procedures [http://man.ac.uk/04Y6Bo] or contact uml.scholarlycommunications@manchester.ac.uk providing relevant details, so we can investigate your claim.

\section{OPEN ACCESS}




\title{
Against the odds? - A study of educational attainment and labour market position of the second-generation ethnic minority members in the UK
}

\section{Yaojun Li}

Xi'an Jiaotong University, China; University of

Manchester, UK

\begin{abstract}
Much research in the UK has shown a close relationship between family position and educational attainment. Yet, this association seems to apply to whites rather than to children from ethnic minority backgrounds who are usually found to outperform whites in spite of their poorer family situation. The classical theories do not give an adequate account of this apparent mismatch as they were designed for the general population. I propose a thesis of 'reinvigorated ambition' to try to explain the second-generation drive for success. Drawing data from the UK Household Longitudinal Study, I show that multiple disadvantages faced by ethnic minorities in the labour market give pervasive signals to the second generation that they have to aim higher and work harder in order not to fall too low in their life trajectory. The educational success of children from ethnic minority heritages can thus be seen as a determined effort to shield off cumulative discrimination in the labour market and in wider society.
\end{abstract}

\section{Keywords}

Class, education, labour market position, second-generation, UK

\section{Corresponding author:}

Yaojun Li, Manchester University, Room 2. I 3f, Bridgeford Street Building, Manchester, MI3 9PL, UK.

Email: Yaojun.Li@manchester.ac.uk 


\section{Introduction}

In the UK as in many other western countries, the second generation are becoming an increasingly more important social force amidst the ageing population of the mainstream group. A lot of research has been carried out on the association between family class and children's educational attainment. Almost unanimously, researchers find that socio-economic conditions of the family origin play a very important role on children's educational attainment. Children from advantaged families outperform their disadvantaged peers and also make better use of the increasing opportunities from the expanding educational services (Breen et al., 2010; Halsey et al. 1980; Shavit and Blossfeld, 1993; Shavit et al., 2007). Immigrants tend to suffer in the labour market and have lower socio-economic resources. One may thus expect their children to do worse in education. Yet, they do not and, frequently, the opposite is found. At least in the UK, the second generation tend to outperform whites from pre-school years to key stage 4 (Cabinet Office, 2017) to higher education (Crawford and Creeves, 2015; Devine and Li, 2013; Khattab, 2009; Leslie and Drinkwater 1999; Lessard-Phillips and Li, 2017).

As Li and Heath (2016) observed, social mobility and ethnic studies scholars tend to operate on separate tracks although they are both concerned with the same issue, that is, whether our society is making progress and whether ascriptive factors such as family background, ethnicity or sex are losing force in shaping people's lives. Thus mobility researchers attach great importance to family resources in terms of parental class, education, income, status or social networks whereas ethnicity students tend to focus on racial/ethnic backgrounds and generational status, making it difficult to see whether theories developed in one domain can apply to another.

In this paper, my interest is to see whether the mainstream sociological theories on people's educational attainment can be fully applied to second-generation's educational attainment. In brief, I would argue that they do not. The reason is that ethnicity constitutes an additional dimension of social stratification not covered in the mainstream theories. Although family circumstances in terms of social advantages and disadvantages affect minorities just as they affect the majority group, ethnic minorities face additional barriers arising from cumulative discrimination in the labour market. These barriers give children of ethnic minority heritages pervasive signals that they are going to face heightened risks of unfair treatment both when they try to find a job and when they wish to make progress in their career life. Thus in order to avoid the setbacks or to lower the risks, they have to aim higher and work harder.

The next section will give a brief account of sociological theories on educational/occupational attainment. I will try to explain why classical theories have neglected the ethnic dimension and ethnic studies have neglected the role of family origin. I will suggest a reformulated framework incorporating insights from both stratification and ethnic studies traditions. Following this, I will present evidence that although educational attainment by the second generation is affected 
by their family origin, the effect is much weaker than for the majority, and that the greater attachment to education by the second-generation is a purposive response to pervasive cues of ethnic disadvantage in employment, career development and income, a demonstration of their determination to provide stronger 'signals' in the form of higher levels of education to offset the likely biases by employers in the selection process. The paper will conclude with some discussion.

\section{A review of the theories on the social stratification of education}

\section{The neglect of ethnicity in classical theories of social mobility}

Quite a few theories have been proposed to explain the association between family background and children's educational attainment. The most influential of these are the modernisation theory (Blau and Duncan, 1967; Treiman, 1970), social reproduction (or 'cultural capital') theory (Boudieu, 1984), rational action theory (or 'relative risk aversion' theory, Breen and Goldthorpe, 1997; Goldthorpe, 2007), maximum maintained inequality (MMI) theory (Raftery and Hout, 1993), and effectively maintained inequality (EMI) theory (Lucas, 2001). While the theories have different analytical focuses, they all attach great importance to the role of family origin in explaining children's educational and occupational attainment. There are variations among the theories but the central themes are the same, as is shown in Figure 1 on the origin-education-destination (OED) relations.

The modernisation theory seeks to advance the thesis of education-based meritocracy. With the economic development and growing government provision of educational services, the role of family background in educational attainment will, as shown in Arrow A for the OE association in Figure 1, gradually decrease as working-class children will be able to catch up with middle-class children, albeit at the lower levels or from lower quality schools (Breen et al., 2010). At the same time, with the exception of some residual economic sectors such as small businesses, direct inheritance from father to son (or to daughter) will lose significance (Arrow $\mathrm{C}$ ), leading to a weakening OD association. The selection process will be

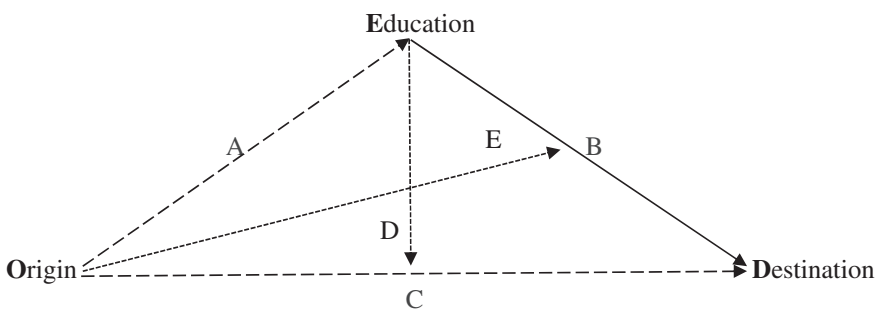

Figure I. The classical framework on the OED association.

Note: Arrow $B$ indicates strengthening and Arrows $A$ and $C$ indicate weakening associations. Arrows $D$ and $E$ indicate moderating effects. 
increasingly merit-based, with educational qualifications assuming greater importance for occupational attainment (Arrow B). There may be some exceptional circumstances, as in the case of highly educated people from poor families finding technical jobs (Hout, 1988) indicated by Arrow D or, as in Arrow E (Goldthorpe, 2016), of advantaged families finding good jobs via social contacts for their children who do not do well in education (although Gugushvili et al., 2017, show that the effect is limited). While debates abound, a common feature in these theories is that family origin is the most important influence on educational and occupational attainment.

While the classic OED places great attachment to the role of family origin, it takes the role as given and does not specify which aspect of family origin would have the greatest importance in facilitating children's attainment. Here the social reproduction theory by Bourdieu (1984) and the rational action theory by Breen and Goldthorpe (1997) provide important insights. For the former theory, middleclass families have superior resources over the working class in the form of socioeconomic-cultural capitals. The strong financial position (economic capital) enables them to send their children to catchment areas with good state schools or to private schools, pay for extracurricular tuition, and buy extra books and other things for their children's development in academic or other areas. They also have friends who know the educational system well and could advise them on their children's educational choices (social capital). Crucially, they have cultural capital, or 'habitus', composed of a system of 'durable, transposable dispositions, structured structures predisposed to function as structuring structures' (Bourdieu and Passeron, 1977: 72). Due to the possession of internalised cultural knowledge and competence, middle-class children are perceived as being well suited to school values and as having high levels of academic capability by middle-class teachers who reward them accordingly. By contrast, working-class families do not have comparable levels of objectified, institutionalised and embodied cultural capital, and do not place a similar level of importance to learning. As a result, their children are seen as lacking aptitude, drive and competence by teachers. It is noted that while all three capitals are emphasised for their roles on social reproduction, Bourdieu (1986: 113) holds that 'economic capital is at the root of all the other types of capital'. Yet, in spite of this emphasis, the concept of cultural capital is seen as his unique, 'signalling', contribution.

Breen and Goldthorpe (1997) disagree with Bourdieu that cultural capital is a key determinant of class differences. For these authors, an emphasis on cultural capital is mistaken. Were the working-class culture as anti-learning as Bourdieu suggests, we would not have seen the large-scale take-up of educational opportunities by working-class children in the last 60 years in the wake of government increase in educational services in the western countries. Working-class children are as aspirational as middle-class children. What is holding them back is not their lack of ambition or motivation but rather their economic constraint, and this constraint is a direct result of the economic insecurity, income instability and financial uncertainty of their families, which is traced to the class positions held 
by their parents (Goldthorpe and McKnight, 2006). It is therefore differences in family positions that explain why working-class children are lagging behind, and it is not the absolute but rather the relative difference in educational outcomes that requires attention. More specifically, the authors hold, although both middleand working-class parents would wish their children to pursue education as a strategy of class preservation, that is, to avoid intergenerational downward mobility, the differential possession of economic resources entails rather different aversions to risks. Backed by superior economic resources, middle-class parents would encourage and support their children to go as far as they possibly could in terms of educational attainment. Working-class families are not in a strong financial position and would, by contrast, advise their children to take 'realistically feasible' options such as leaving for the labour market early to make money or attending vocational courses in local colleges. The class differences manifest themselves in different approaches: 'strategy from above' for the middle class and 'strategy from below' for the working class. While equally rational, the differences in class-lined resources channel them into different strategies.

Comparing the two accounts, one can see differences in the theoretical perspectives and similarities in the operational procedures as well. Thus, habitus, or family cultural capital, is still measured by Bourdieu in terms of 'the academic level of the forbears' (1977: 497) in spite of the encompassing and nebulous characteristics in the definition. On the other hand, even though Goldthorpe attaches great importance to class as the overarching character of family position, he seems to have increasingly come to the view that a multivariate rather than univariate approach is a better representation of family social position, including parental income, education, status and networks as well as occupational class (Gugushvili et al., 2017). The list is comprehensive, incorporating socio-economic-cultural resources as advocated by Bourdieu (1997), Coleman (1988) and Lin (1990). Another commonality, which is of greater importance to the present purposes, is that, like the modernisation theory, these accounts are geared at the origin-educational association of the general population, with the implication that the pattern of association would be universally found, for ethnic minorities just as for the majority group.

\section{The inadequate attention to family position in accounts of ethnic studies}

With regard to ethnic studies, scholars have proposed different accounts of secondgenerational educational attainment which are not as powerful as those in stratification studies. The most notable of these is the segmented assimilation theory by Portes and his colleagues (Portes and Zhou, 1993; Portes et al., 2009). The theory contains a three-pronged model: consonant, selective and dissonant acculturation characterising three distinct groups. The first pertains to professional immigrants and their children who undergo a process of consonant acculturation where they jointly learn and accommodate to the language and culture of the host society leading to exceptional educational and occupational mobility into the mainstream elite. The second group is similar to the first but with lower levels of human capital. 
Yet their stronger community embeddedness enables them to adopt a selective acculturation where language learning and cultural inheritance proceed simultaneously leading to successful labour market position and community preservation. By contrast, children of working-class immigrants who lack human capital and who have weak community support will typically experience dissonant acculturation, with introjection of host-society values and rejection of parental culture, ending up in the underclass. The theory appears elegant and seems to offer a class-lined account similar to the mainstream theories in the mobility tradition. Yet whether the three kinds of acculturation could be found in reality and how effective they are remain an open issue. In a vigorous analysis of seven educational and occupational outcomes ranging from dropout to professional occupancy for second-generation young adults in New York, Waters and her colleagues show that only $10 \%$ of the respondents in the sample belong to the dissonant group and that even among these, hardly any barrier of communication exists between parents and children. Many young people from disadvantaged families such as the Chinese whose parents worked in restaurants or garment factories managed to make exceptional educational achievement in spite of their humble origins. In sum, Waters and her colleagues hold that dissonant assimilation is the exception rather than the norm and does not have the kind of negative impact as the theory expects, nor does selective acculturation guarantee educational or occupational success. Waters et al. conclude that 'type of acculturation hardly matters for any of the outcomes' (2010: 1185).

Another thesis on second-generation, especially Asian, young people's educational success is that of 'immigrant optimism' proposed by Kao and her colleagues (Kao and Thompson, 2003; Kao and Tienda, 1995). They find that 'immigrant parents promote academic achievement' (Kao and Tienda, 1995: 1). Immigrants are a highly self-selected group who possess higher levels of drive and determination than their compatriots who stay in their country of origin, and this may serve as a source of inspiration for their children's optimism and educational success. Asian children do better than Hispanic or Black children, but it is not shown whether this is due to the longer distances Asian parents have to travel from their countries of origin to the USA, hence more positively selected, or to greater poverty in the origin countries of the Asian relative to the Hispanic or Black immigrants, or to the greater tradition of learning in Asian culture leading to a pro-learning milieu in the family. Similar accounts of parental encouragement are given in the UK context by Connor et al. (2004) and Modood (2004). Modood holds that the educational success of South Asian and Chinese students lies in 'migrant parents getting their children to internalise high educational ambitions and to enforce appropriate behaviour' (2004: 87). The underlying idea is that South Asian and Chinese groups are able to exercise their 'ethnic capital' despite their socio-economic disadvantages (see also Shah et al., 2010) with the ethnic capital being composed of close relationships, strong norms and tight community ties. The account is reminiscent of Coleman (1988) and Portes et al. (2009) and seems convincing on South Asian communities although it does not explain why 
the majority group does not have similar levels of ambition. Connor et al. suggest a thesis of 'lower opportunity cost' in explaining the higher rates of continuing education beyond compulsory school leaving age for ethnic minority children. The unemployment rates for young people are higher and earnings are lower for younger than for older people, leading ethnic minority parents and children to prefer staying longer in education in the hope of obtaining relatively greater returns to education. But this thesis does not establish whether the opportunity costs are lower for ethnic minority young people than for their white peers and, if so, why.

Summing up, we can see that there are powerful theories which provide competing but inadequate accounts of second-generation educational attainment in Britain. The mainstream stratification theories from the classical modernisation theory to the social reproduction theory and the rational action theory give no specific attention to ethnic differences in the origin-educational association; the segmented assimilation theory lacks empirical grounding; and the theses of ethnic optimism, community support and lower opportunity cost do not explain why the optimism or support is available to some of the minority groupings but not to others nor to the majority group, and why ethnic minorities could make a better use of the opportunities than do their white peers.

\section{A reformulated thesis on reinvigorated ambition for second-generation education}

Given the inadequacy in the existing accounts on the educational attainment of ethnic minority groups, I wish to venture an alternative thesis. I would argue that ethnic minority young people's decision to stay longer in education is due to their anticipation that there will be greater difficulties for them than for whites in finding employment and gaining career advancement. From their parental experiences and what they have observed among their co- or pan-ethnics, they would expect raised thresholds initially in recruitment and later in training and promotion opportunities. Given their understanding of the high levels of odds running against them in the future career life, they would wish to make preparations to fight against the odds. Recruitment processes consist of application, shortlisting and interviewing. In a well-known field study, Wood et al. (2009) show that hypothetical job seekers who had the same personal attributes and the same type and level of education from UK universities, and who were only different in names (some with typical white names and others with typical black, South Asian or Chinese names) faced rather different outcomes: those with apparently ethnic minority names had to send around twice as many application letters as their white peers to get a callback for interview, a figure that remained almost unchanged for the last few decades. Similar findings are reported in Austria, Germany and the Netherlands (Blommaert et al., 2014; Forstenlechner and Al-Waqfi, 2010). There is no research currently available on differential 'success' rates by ethnicity at interviews but it would be surprising if employers only show biases at the short-listing stage and no bias exists at appointment, retention or promotion. In the absence of hard evidence 
at the crucial later stages, it would be reasonable to suggest that data on unemployment and career profiles from national representative surveys would be the best indicator of the differential risks faced by different ethnic groups. Such data are not only the actual lived experiences but could also be perceived as the likely 'fates' for them when they enter the labour market.

In view of this, I propose a reformulated framework on ethnic educational and occupational attainment incorporating insights from both mobility research and ethnic studies, as shown in Figure 2. There are two triangles in this figure, the inner one for the majority and the outer one for the ethnic minority groups. On the ED link are added 'candidates signalling' and 'employer screening', the two components of the certifying processes at recruitment. There is a loop-back from the ED to ethnicity (Arrow D) to serve as perceived risks, and a link (Arrow E) from ethnicity to origin which suggests amplification of the ethnic minority origin effect. Both parents and young adults are assumed capable of evaluating the heightened risks that they are going to face in the absence of an 'educational advantage', and are prompted to make joint decisions on the need to make extra efforts by staying longer in education. If, for instance, it takes a young white person an ALevel qualification to get a job as a bank cashier, they might need to have a college education for a similar job. Arrows D and E, together with information from family economic circumstances and wider social milieu in Figure 2, would serve to explain why second-generation ethnic minorities would aim higher in education: they have to do this in order to escape the perpetuation of poverty.

At the heart of this reformulation is the perception of risks at the recruitment processes and in the career paths, risks that are 'personified' by lived experiences of parents, kin and other co-ethnics, acutely felt from the immediate social milieu including family poverty and local deprivation, and 'embodied' in the communications among parents, between parents and children, and amongst children. At the recruitment stage, employers tend to select the 'best' candidates, a certifying process in which applicants of all ethnic backgrounds will seek to give employers the strongest possible 'signals' with regard to their creative potential, adaptability and employability, and employers will try to 'screen' them, namely, to find the candidates with the highest productive potential and the lowest training costs

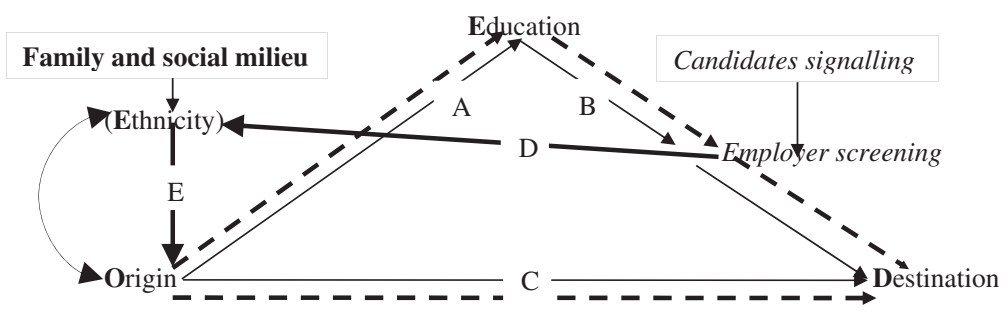

Figure 2. A reformulated framework for ethnic research.

Note: The inner OED triangle is for the majority and the outer triangle for the ethnic minorities. Social milieu refers to co- and pan-ethnic experiences. 
(Goldthorpe, 2014; Spence, 1973; Weiss, 1995). It is noted here that 'productivity' needs to be understood in a broader sense, including not only physical output but also 'fitness' within the organisational culture and environment. As suggested in Figure 2, ethnic minority youth may be well aware, given their knowledge of the barriers to employment as encountered by their parents, kin and other co-ethnics, of the lower call-back rates for interview and higher rejection rates even when they do obtain an interview. In order to compensate for the lower call-back and higher rejection rates, young people of ethnic minority heritages would try to convince themselves that they need to be better 'prepared', that is, to be able to present prospective employers with higher levels of educational qualifications than their competitors. They do so in the anticipation that employers in the screening process may well give a lower 'weight' to the qualifications they possess relative to those held by applicants from the majority group; thus, by being able to present higherlevel qualifications, they wish to impress prospective employers about their higher levels of commitment as well as human capital, which they hope may countervail against the lower weight bestowed upon their qualifications. If this reasoning is correct, their investment in education is not due to their taking greater advantage of lower opportunity costs, having greater optimism arising from immigrant backgrounds, conducting more precise calculation of realistic feasibility, holding higher internalised ambition, or forging stronger community embeddedness. These features may take place, but would be seen as being of marginal importance. The most decisive factors in the reformulated framework are their understanding of ethnic inequality in general and unfair treatment in the labour market in particular, features that are rooted in the overt or covert forms of racial discrimination that may still be existent in our society.

The cues from recruitment processes may be reinforced by parental setbacks and the overall level of poverty in the family and the local community. In addition, young people of ethnic heritages may be aware that they are not only less likely to find a job at similar educational levels to whites, but also more likely to face career frustrations even with similar or more efforts on the job. Furthermore, prior unemployment histories may have a more adverse impact on them than on their white peers in terms of re-employment and career advancement. In short, they would understand that they have to make a greater investment in education, as there may be more barriers for them to surmount in the labour market. Ideally, one would wish to have direct evidence on the outcomes of the screening process (Arrow D in Figure 2) but given the lack of such data as earlier noted, we could only use indirect evidence. On the other hand, population statistics on unemployment and career advancement would serve as the best and most objective evidence of such outcomes.

In light of the foregoing discussion, the following research questions will be addressed in the present analysis:

1. Does family class explain educational attainment for second-generation ethnic minority groups to a similar extent as it does for whites? In other words, is there a significant moderating effect of ethnicity on the O-E association? 
2. Do ethnic minority groups face heightened risks of unemployment over the life course?

3. Do ethnic minorities face marked disadvantages in career advancement?

4. Do ethnic minorities experience higher levels of poverty than do whites?

If the answers to the questions are in the affirmative, indicating pronounced ethnic disadvantages, we would have sufficient grounds to believe that, even in the absence of direct evidence of employer bias in the selection, retention and promotion processes, there are significant warning signs for parents and children from ethnic minority backgrounds to take seriously, as a 'fact of life'. As minorities in the white-dominant society, they would constantly remind themselves that to survive and thrive, they have to strive, firstly in education, and then in work.

\section{Data and methods}

To address the research questions as outlined above, I will use data from the UK Household Longitudinal Study (UKHLS) for the analysis (University of Essex, 2016). The UKHLS started in 2009 and is arguably the largest and best panel survey currently available. From wave 2 onwards, it contains the 'rolled-in' sample from the British Household Panel Survey (BHPS). The data have the advantage of including a large boost of ethnic minorities and have the variables needed for the present analysis.

To answer the questions on educational attainment and family poverty, I use data from the first three waves of the UKHLS, confining the analysis to the second-generation aged 21-64 with valid information on parental class, ethnicity and education $(N=35,744$, with 3,768 second-generation ethnic minority respondents). Second-generation is defined as those of ethnic minority heritages born in the UK or arriving by age 16, following Connor et al. (2004). ${ }^{1}$ Given the focus on degree-level education, it would be reasonable to assume that the second generation thus defined will have received their degree education in the UK. For labour market position, data from all six waves available at the time of analysis are used, for the working-age population (men aged 16-65 and women aged 16-63 excluding full-time students, $N=57,805$, observations $=202,878$ ). For ethnicity, the standard census coding is used, including white, black Caribbean, black African, Indian, Pakistani/Bangladeshi, Chinese, and 'Other'. For parental class, the dominance approach is adopted using the National Statistics for Socio-Economic Classification (NSSEC) schema, including (1) higher salariat (professionals and managers of higher grades and large employers, Class I), (2) lower salariat (professionals and managers of lower grades plus non-manual supervisors, Class II), (3) routine white-collar employees (clerical and other routine non-manual workers of higher grades, Class IIIa), (4) small proprietors, own account and farmers (Class IVabc), (5) manual supervisors and lower-grade technicians (Class V), (6) skilled manual routine workers (Class VI), and (7) semi- and unskilled routine workers 
(lower-grade routine non-manual workers, semi and unskilled manual routine workers, and agricultural labourers, Class IIIb + VIIab).

\section{Results}

\section{The origin-education association by ethnicity}

We have seen in the above that the mainstream sociological theories attach great importance to family position in accounting for people's educational attainment and that although exponents of the social reproduction and the rational action theories have different theoretical focuses, they are not so different when it comes to the operationalisation of family position. Following standard practice, I will start by establishing the link between family class and respondent's educational attainment. Data in Figure 3 show the origin-education (O-E) association by ethnicity, differentiating between white and second-generation respondents. For simplicity, only highest (first degree or higher) and lowest (primary or no formal education) levels of education are shown in Panels 1 and 2, respectively (data on the other distributions are available on request). The data show a very strong association between one's family class and educational attainment. People from higher salariat families are most likely to have degree-level education and least likely to have only primary or no formal education, and those from both the majority and the minority ethnic backgrounds tend to follow this overall pattern, rendering general support to the theories. Yet, we also see clear ethnic differences. The lower the family class, the greater the ethnic differences in degree- and primary/no education. For respondents from higher salariat families, ethnic differences are fairly small, at 7 percentage points $(52 \%$ and $59 \%$ for white and ethnic minorities), but the differences become bigger as we go down the class categories. For people from routine working-class families, only $10 \%$ of whites have degrees but $22 \%$ of the second generation do, with a difference of 12 percentage points. The gaps are even more salient at the lowest level of education, from 2 percentage points among the higher salariat children to 18 points among the workingclass children.

It may be objected that using parental class alone as in Figure 3 does not fully capture the family resources. Exponents of both social reproduction and rational action theories have suggested that parental education, social status as well as occupational class are important factors. There may also be important demographic differences between the majority and the minority groups. Furthermore, as other studies (Boliver, 2016; Connor et al., 2004; Lessard-Phillips and Li, 2017; Platt, 2011) have shown, there are considerable differences among ethnic minority groupings which may be larger than between them and the whites. Given this, further analysis is conducted on ethnic differences, focusing on degree-level education. The results are shown in the form of average marginal effects (AME) derived from logit regressions. ${ }^{2}$ It is noted here that both age and age squared 


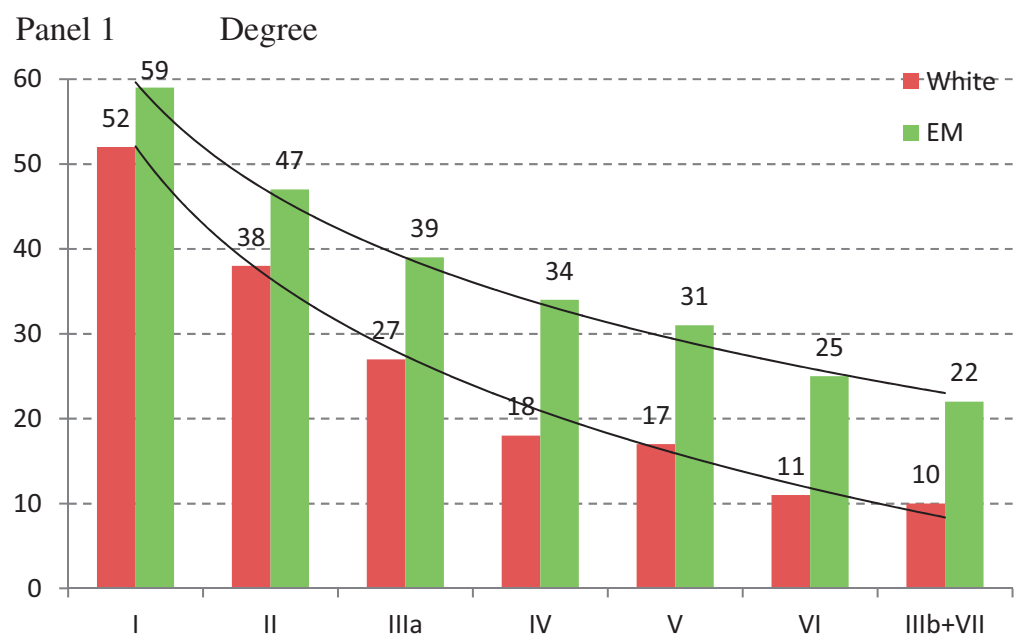

Panel 2 Primary or no formal education

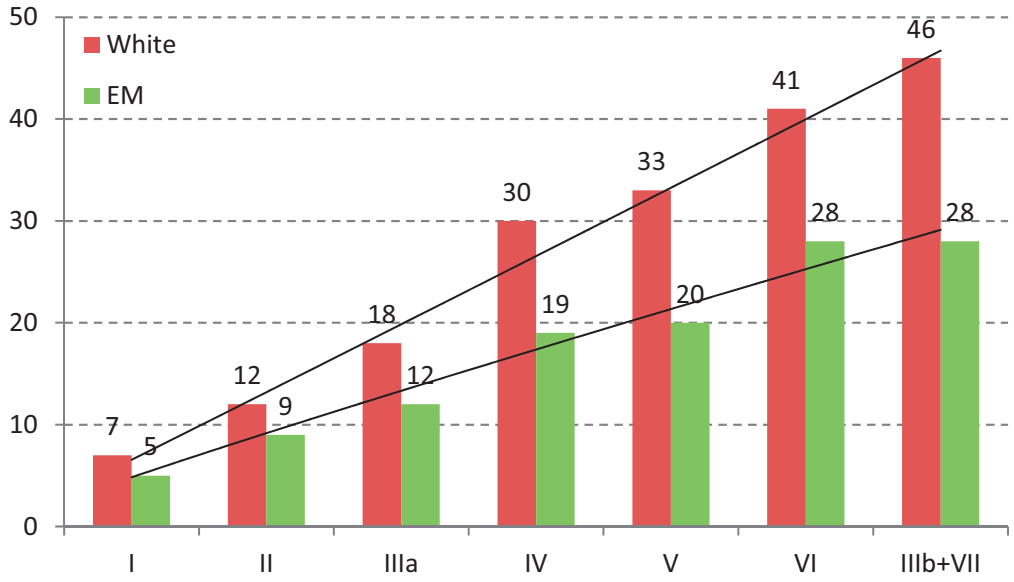

Figure 3. Distribution of respondent's education by parental class and ethnicity. (Panel I) Degree. (Panel 2) Primary or no formal education. Source: The UKHLS (waves I-3).

are entered into the model but are incorporated as age effect in the AME. The data in the table represent percentage-point differences.

Table 1 shows clear and significant parental effects for whites but not so for the ethnic minority groups (except for the 'Other' group). White working-class children are around 30 percentage points behind their higher salariat peers in having a degree, net of all other factors controlled for in the model. Ethnic minority members from lower-class origins are also less likely to have degrees than their higher salariat peers but what is striking is the lack of significant difference. If anything, 
Table I. Average marginal effects on degree-level education.

\begin{tabular}{|c|c|c|c|c|c|c|c|}
\hline & White & B Car & B Afr & Indian & $P / B$ & Chinese & Other \\
\hline \multicolumn{8}{|c|}{ Parental position } \\
\hline Tertiary & 0.091 *** & -0.000 & 0.033 & 0.059 & 0.048 & 0.008 & $0.086 *$ \\
\hline ISEI & $0.001 * * *$ & 0.003 & 0.004 & 0.003 & 0.003 & 0.006 & -0.001 \\
\hline \multicolumn{8}{|l|}{ Class $(\mathrm{I}=\mathrm{ref})$} \\
\hline II & $-0.106 * * *$ & -0.125 & -0.153 & -0.090 & -0.047 & -0.126 & -0.077 \\
\hline IIla & $-0.170 * * *$ & -0.121 & -0.004 & -0.130 & -0.046 & -0.028 & -0.088 \\
\hline IV & $-0.24 I * * *$ & -0.062 & -0.234 & -0.158 & -0.186 & 0.033 & $-0.209 *$ \\
\hline V & $-0.237 * * *$ & -0.202 & -0.269 & -0.088 & -0.073 & 0.057 & $-0.219 *$ \\
\hline VI & $-0.295^{* * * *}$ & -0.171 & 0.088 & -0.191 & -0.155 & -0.138 & $-0.326 * *$ \\
\hline IIlb + VIlab & $-0.297 * * *$ & -0.074 & -0.356 & -0.203 & -0.125 & $-0 .|| \mid$ & $-0.404 * * *$ \\
\hline Female & -0.007 & $0.116 * *$ & -0.083 & $-0.126 * *$ & -0.020 & -0.128 & -0.006 \\
\hline Age & $-0.00 \mathrm{I} * * *$ & -0.003 & $0.018 * * *$ & -0.003 & -0.004 & 0.015 & 0.003 \\
\hline$N$ & 29713 & 536 & 232 & 690 & 769 & 75 & 732 \\
\hline
\end{tabular}

B Car: black Caribbean; B Afr: black African; P/B: Pakistani/Bangladeshi. ${ }^{*} \mathrm{p}<0.05$, ${ }^{* *} \mathrm{p}<0.01$, ${ }^{* * *} \mathrm{p}<0.001$.

black Africans from skilled manual, or Chinese from own-account or manual supervisorial, families (who are likely to be take-away owners or chefs in restaurants) are equally or slightly more likely to have a degree than their higher salariat peers. It is noted here that the sample sizes for the ethnic minority groups (except for Chinese) are not small, and the failure to reach conventional significance lends further support to the argument that parental effect on education is weaker for ethnic minorities than for the majority group, echoing findings on class attainment ( $\mathrm{Li}$ and Heath, 2016). ${ }^{3}$ At each level of parental class, especially at the lower levels, ethnic minorities have higher levels of education than their white peers.

\section{Unemployment risks, career setbacks and family poverty}

The analysis above shows that at both gross and net levels, family class differences are less salient for ethnic minorities than for whites. The intriguing question is why this is the case. There could be many reasons. Immigrant parents who have trekked long and hard journeys tend to find themselves in suppressed class positions and they would wish their children to avoid repeating their hardships. Most immigrants would have unforgettable memories of how helpless they were upon arrival, how their educational qualifications were little valued, and how difficult it was for them to make ends meet. Even those currently holding relatively comfortable positions may have experienced long and harsh survival struggles, frustrations and failures. Those who were UK born or who came at young ages and were educated in UK universities may also recall how badly they were treated during the economic downturns, being 'first out and last in' when mass unemployment occurred (Li, 2015). In addition to personal experiences, ethnic parents would have kin, 
friends, neighbours and acquaintances from co- or pan-ethnic networks with similar stories. Such lived and shared experiences would be the 'springs' of information constantly flowing into the minds of their children who could also see with their own eyes how their co-ethnic fellow students fare when they enter the labour market.

The following analyses that focus on labour market position and family poverty are intended as cues to the loops noted above (Arrows D and E in Figure 2). Quite a few studies have been conducted on ethnic unemployment during the last 30 years, including that between first and second generation, on 'hyper-cyclical' unemployment, and for second-generation graduates (Heath and Li, 2008; Khattab and Modood, 2015; Khattab and Johnston, 2013; Li, 2015, 2017; Li and Heath, 2008, 2010, 2017). Yet such studies were based on cross-sectional data and were unable to reveal the dynamics over the life course. In view of this and with the aim to provide the latest information, this analysis will be based on the first six waves of the UKHLS.

The data in Figure 4 show the pattern of unemployment for men and women, respectively. The data are predicted values from multilevel growth-curve models controlling for time-constant (ethno-generational status and region) and timevarying (age, age squared, education, and marital and health status including the education*ethnicity interaction) effects, and with the effects of random intercepts and random slopes incorporated (the modelling tables are not shown but are available on request). ${ }^{4}$ Young people are highly vulnerable to unemployment but whites, Indians and Chinese were much less likely than other groups to face unemployment, around half as likely. From around age 30 onwards, White and Chinese men's employment situation becomes quite stable whilst Indian men begin to face greater risks of unemployment. The ethnic penalties for black Caribbean and Bangladeshi men are pronounced, with the former experiencing around 2.5 to 3 times the risks of unemployment as their white peers and the latter experiencing sharp increases of unemployment starting from around age 35, culminating at around five times of risks relative to those for white men. ${ }^{5}$ The shape for women's unemployment is generally similar to that of men, with the exception that from around age 45 onwards, Pakistani and Bangladeshi women's unemployment rates start to go on a steady rise while the rates for most other groups keep falling. Pakistani/Bangladeshi women's unemployment profile is of a U shape whereas that for the other groups is on the decrease as people become older. From around age 25 to age 50, there is little difference between Chinese, Indian and white women, but the two black groups are around twice as likely to be unemployed. Most Muslim women (around 60\% in the data) are economically inactive but those who are actively seeking a job and who could thus be regarded as exceptionally 'positively-selected' are, as shown in the data, faced with mounting barriers as they became older. Further analysis shows marked 'scarring effects' of prior unemployment and the 'ethnic penalties' in the scarring effects. For men and women without unemployment histories in the period covered, ethnic minorities tend to have unemployment rates around ten percentage points higher than those 


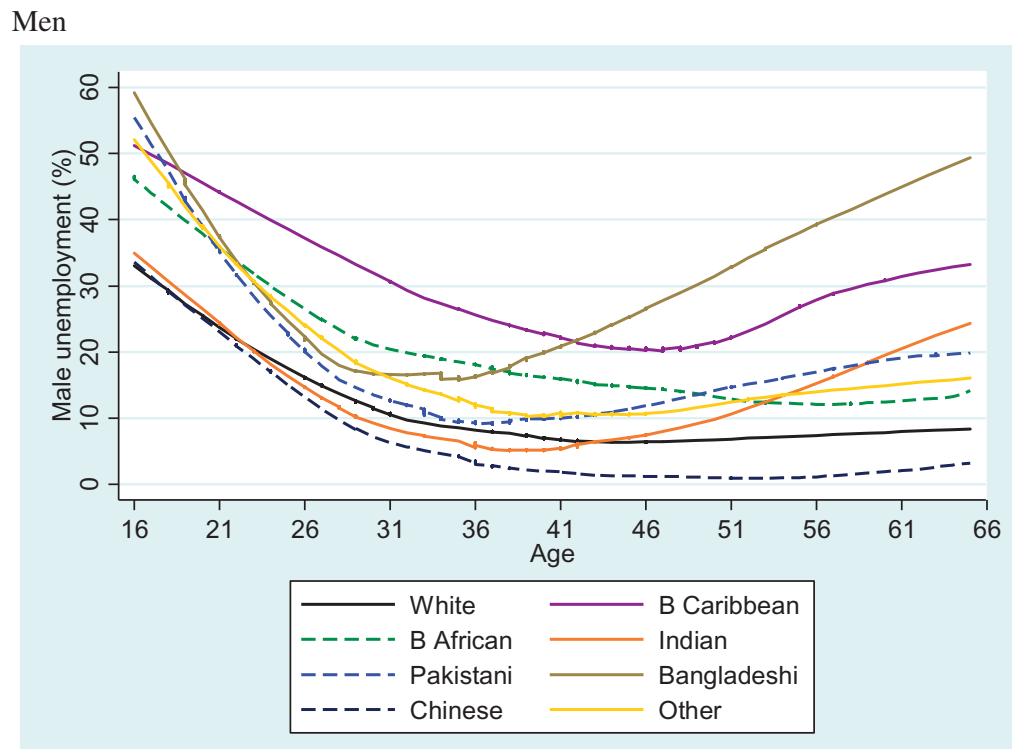

Women

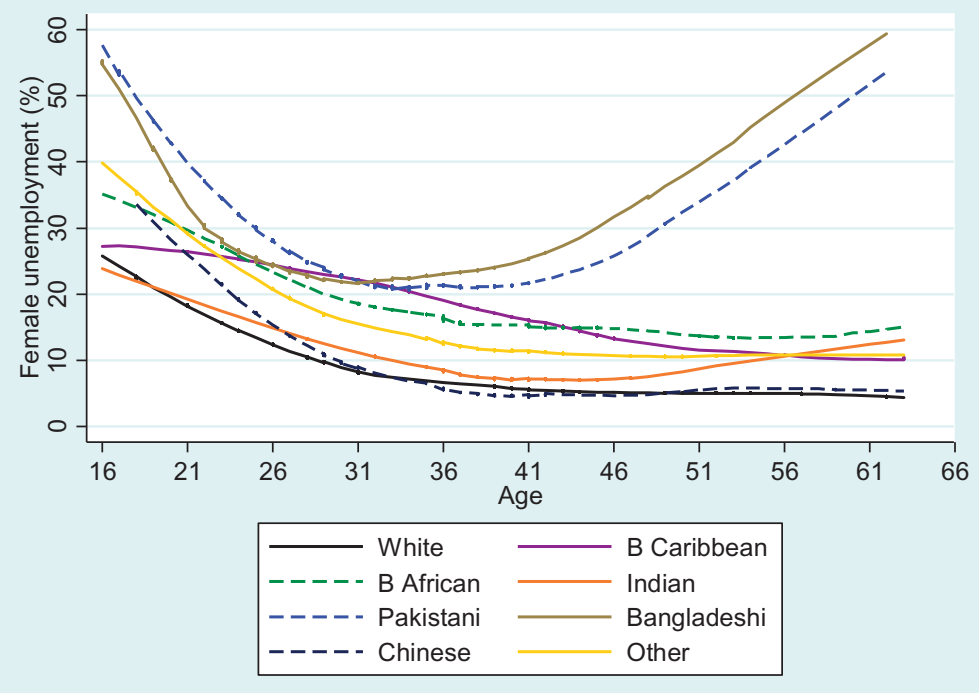

Figure 4. Risks of unemployment over the life course.

for whites, but for those with prior unemployment histories, black Caribbean men and Pakistani women again have unemployment rates being 10-15 percentage points higher than their white peers. All this suggests that prior unemployment does have a scarring effect as Arulampalam et al. (2001) and Bell and Blanchflower 


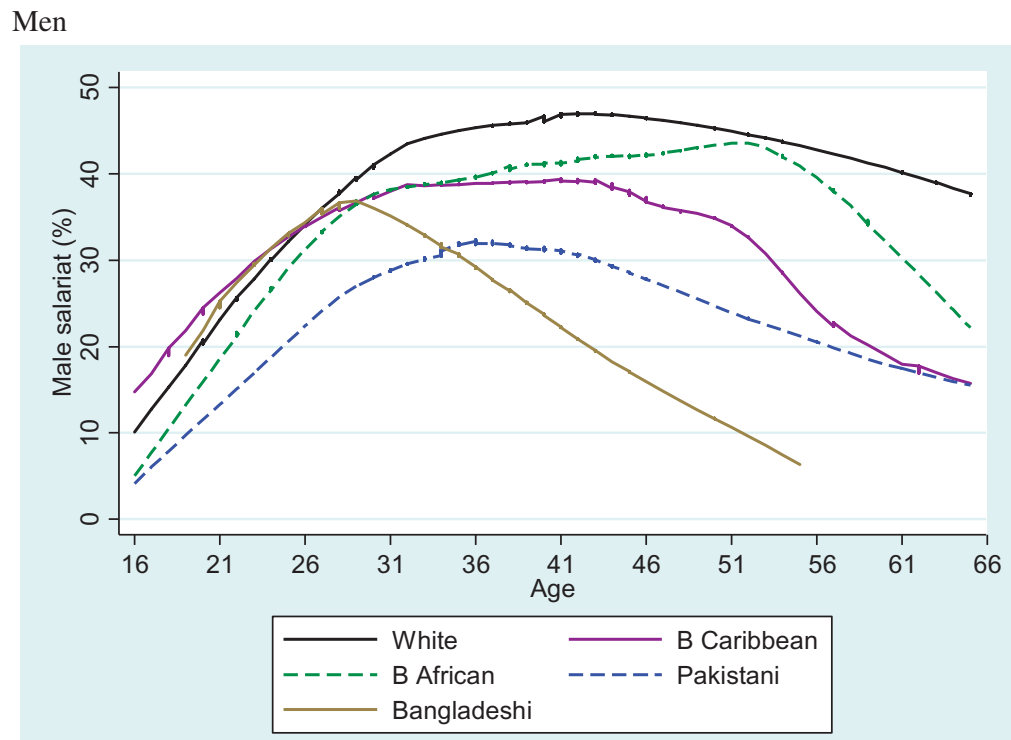

Women

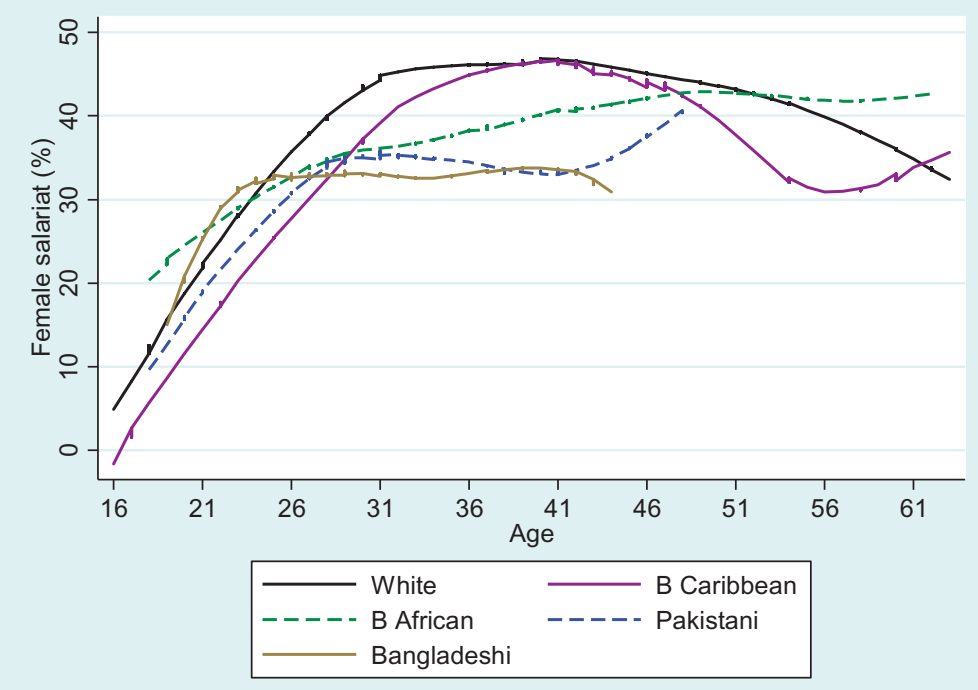

Figure 5. Access to professional-managerial positions over the life course. Note: Data points are dropped where $\mathrm{Ns}$ are less than 10. 


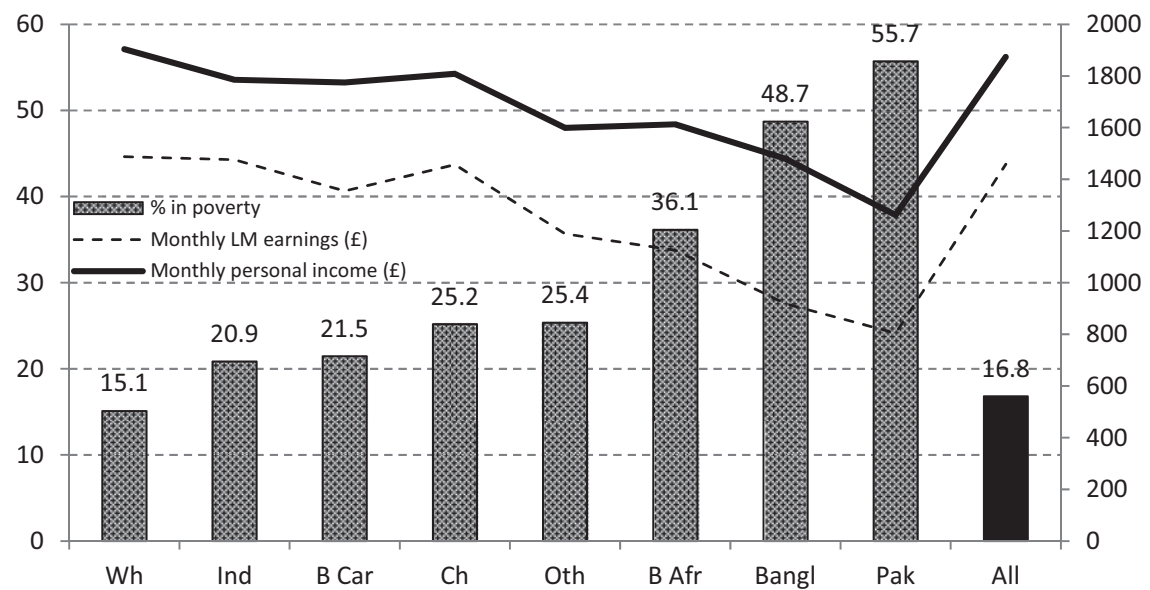

Figure 6. Labour market earnings, personal incomes and family poverty by ethnicity. Note: Wh: white, Ind: Indian, B Car: black Caribbean, Ch: Chinese, Oth: Other, B Afr: black African, Bangl: Bangladeshi, Pak: Pakistani. For men aged 16-65 and women aged 16-63 with valid responses on ethnicity, pooled data from waves I-3 of the UKHLS.

(2010) argued, and that the effect is much more pronounced for minorities than for whites, particularly so for blacks and Muslims, echoing previous analysis by Heath and Martin (2013) and Khattab and Modood (2015).

While actively seeking but being unable to secure a job is a gruelling experience, seeing similarly qualified colleagues getting promotions whilst remaining stuck in one's own career is equally frustrating. To see how career life differs by ethnicity, the analysis is now turned to access to advantaged professional-managerial salariat positions. People in this class tend to have secure employment, stable incomes and steadily advancing prospects. The data are shown in Figure 5, with results obtained in similar fashions to those in Figure 4. As Indians and Chinese are little different from whites in their career profiles over the life course, data for the two groups (and for the 'Other') are omitted to aid exposition.

The shape on salairat access is the mirror image of that on unemployment risks. Just as in unemployment, ethnic differences abound. Even in the prime of life, black Caribbean men are, other things being equal, around 10 percentage points and Pakistani men 20 points behind white men in gaining a foothold in the salariat. Equally notable is the finding that the 'career blossom' starts to wither much earlier for ethnic minorities than for whites. For white men and women, the decline in salariat occupancy proceeds slowly and smoothly, without abrupt disruptions. For black African men, the decline starts in the early 50s and precipitates afterwards. For black Caribbean men, the decline starts even earlier, in the early 40s. Pakistani and Bangladeshi men do not even have a career stability to speak of: they begin the downhill journey as soon as they reach the top, in the mid-30s and late 
20 s, respectively. White women are also seen to have a clear advantage: they stay in salariat positions for much longer than do their ethnic minority peers over the life course and, at the peak of their careers, say between age 30-45, have a lead of 7-8 percentage points over black African women, and around twice as many points over Pakistani/Bangladeshi women, in the occupancy of salariat positions.

Having looked at the disadvantages in the labour market, I turn to what might be called 'cues' from 'family and social milieu' as shown in Figure 2. Space limit prevents discussion on social deprivation (see Cappelari and Jenkins, 2007) and I will focus on family poverty as the most direct impetus on the second-generation drive. As can be expected, the weaker positions in the labour market would land ethnic minority families in a strained economic situation, which is clearly shown in Figure 6. Here three kinds of data are presented: monthly earnings and personal incomes, and risks of poverty (for details of measurement, see Heath et al., forthcoming). On each of the three measures, whites are at an advantage: they have a personal income of $£ 1,904$ per month, which is $£ 642$ more than Pakistanis; and they have a monthly pay of $£ 1488$, which is nearly twice as high as that of Pakistanis, at $£ 805$. The most salient ethnic differences manifest themselves in terms of family poverty: $36 \%$ of black Africans, $49 \%$ of Bangladeshis and $57 \%$ of Pakistanis are living in poverty as compared with $15 \%$ of whites.

\section{Discussion and conclusion}

Large-scale immigration to the UK occurred after the Second World War and at the present time, around $15 \%$ of the population consist of people of minority ethnic heritages. An increasing portion of them are second or even third generation who have come of age and are entering the labour market in large numbers. Ethnic differences in education, employment and career trajectories as rooted in cumulative discrimination are commanding serious attention from social scientists and government decision-makers. Promoting socio-economic integration of ethnic minority communities is not only a matter of upholding the principles of equal opportunity and social justice as enshrined in the law, but also that of safeguarding our national prosperity and economic sustainability, given the ageing structure of the mainstream group. Many studies have shown persisting ethnic disadvantages in British society and Prime Minister Theresa May recently (on 12 October 2017) said that we as a society must 'explain or change' such persistent inequalities.

Explaining ethnic inequalities is not a straightforward task. We do not have hard evidence on 'direct discrimination' relating to employer bias at short-listing, interview, appointment, retention, promotion or dismissal. Social scientists tend to prefer a procedural rigour in trying to establish a 'causal' fact, requiring an antecedent to have a significant impact on an outcome. In much of the ethnic research, the practice tends to try to establish a statistical association rather than an epistemological causation. The well-known concept of 'ethnic penalty' is a case in point although the explanatory variables in the models are assumed to have 
occurred prior to the outcome variables. Temporal precedence in variables is, however, not the same as group preference in the decision-making processes.

This paper has taken a somewhat different approach, using labour market experiences in terms of unemployment risks and career development over the life course, and personal and family economic situation, as cues on ethnic origin differences in second-generational educational attainment. The analysis in the paper shows that at the same level of parental class, the second generation tend to have higher educational qualifications, and 'ethnic premiums' are especially note-worthy at the lower classes. This feature is not expected from the perspectives of mainstream sociological theories, nor is it adequately explained by accounts of segmented assimilation theory or immigrant optimism or ethnic capital. As shown in Figure 3 and Table 1, whilst there is a class gradient for all social groups, there is a marked ethnic difference, with the second-generation outperforming whites regardless of parental class. What is more, in Figure 6, we saw marked differences in family poverty by ethnicity. The second-generation's greater drive thus cannot be due to greater 'cultural capital' (one third of white parents have tertiary education but only one in five ethnic minority parents have such education), nor to more advantaged family class $(34 \%$ of white parents as against $30 \%$ of ethnic minority parents are in the salariat), nor to higher levels of optimism, stronger community bonds or greater strengths ensuing from such bonds relative to whites. It would be hard to assume that just because ethnic communities are poorer, there must, therefore, be greater 'ethnic social capital' within their communities, commanding a mysterious 'solidarity in adversity'. Ethnic minority communities may indeed have a unique kind of ethnic capital, so do the more affluent white communities. It would be stretching our imagination to use thinly shrouded concepts of ethnic optimism or community cohesion which may be at a much lower level than that found in the white community to explain why and how secondgeneration ethnic minority members succeed in education against all the odds.

To try to explain the ethnic minority educational success, I argue that the social milieu, whether perceived, lived or experienced, and in all the main domains and manifestations, need to be taken into account. Here perceived unemployment risks are at once the first and most crucial consideration. Research has shown sufficient evidence on differential call-back rates for interview (Blommaert et al., 2014; Forstenlechner and Al-Waqfi, 2010; Wood et al., 2009), and legal complications prevent the collection of data during interviews. Whilst we cannot see what is happening during the process, we can find out what comes out of the decision-making, in the hiring and firing rates, promotion probabilities, earnings levels and poverty risks all of which serve as powerful cues and constant reminders. Following this logic, the present study has, using the most authoritative data sources available, shown patterns of ethnic unemployment and salariat occupancy over the life course and of family poverty. In both aspects of life-course trajectory, ethnic minorities are found to face much greater risks than do their equally qualified white peers.

While several Race Relations Acts have been enacted to reduce ethnic disadvantages in the labour market and other aspects of socio-economic life, the 
problem of racial discrimination has not been eradicated. As clearly shown in the paper, there are marked and persisting ethnic disadvantages in unemployment, access to salariat and family poverty. It is inequalities such as these which would feed into the educational decision-making by ethnic minority parents and their children. Ethnic parents would urge their children to aim higher and work harder, and the advice is usually followed. Yet, in spite of this, they are still found to fare worse when they come to the labour market. So, a question is raised in this regard: were they being rationale in deciding to go the extra mile? Perhaps an appropriate answer lies in raising another question: what would have occurred to them if they had not tried so hard?

The thesis of 'reinvigorated ambition' by second-generation ethnic minorities in the UK as proposed in this paper is a tentative one, as it derives the rigour from the 'feedback' loops, that is, by taking evidence of ethnic disadvantage in the labour market and of family poverty as cues to the decision-making impetus. This, in a sense, is a 'retrospective' study. In future, it might be useful to design a 'prospective' study by tracing the educational trajectories of young people from different ethnic heritages whilst using family employment and poverty histories as feeds into the decision-making at critical junctures, such as transition from A-Level to degree education or from under- to post-graduate studies. In such a study, one could explore whether a structural approach as adopted in this paper or a cultural approach as advocated in some of the other accounts as earlier discussed would find stronger support and whether, within such a structural approach, there is evidence for an ethnic version of the 'relative risk aversion' (RRA) theory, namely that whereas the RRA for the majority group is to avoid intergenerational downward mobility, ${ }^{6}$ that for the minorities is to avoid intergenerational stability in poverty and to strive for intergenerational upward mobility. We could foresee a scenario where the thesis would no longer hold: if no ethnic disadvantages are found to persist in the labour market after the most rigorous tests whilst the ethnic educational drive is keeping the momentum. In such a case, ethnic educational excellence would be truly aspirational and intrinsic. Let us hope that such a day would come sooner rather than later but before it comes, society has a responsibility to 'change' as Prime Minister May says, and to eradicate racial discrimination.

\section{Acknowledgements}

I am grateful to Professors Nabil Khattab, Tariq Modood, Anthony Heath and Dr Alita Nandi for their helpful suggestions during the conceptualisation, analysis and writing of this paper. Earlier versions of the paper were presented at the seminars held at Bristol University in September 2015, at Manchester University in February 2016, and at Essex University in October 2016. I wish to thank the attendants for their comments. I also wish to thank the Institute for Empirical Social Science Research (IESSR), Xi'an Jiaotong University, China for providing facilities for conducting much of the analysis reported in the paper during my stay there as a visiting professor. All errors in the paper remain mine. 


\section{Declaration of conflicting interests}

The author(s) declared no potential conflicts of interest with respect to the research, authorship, and/or publication of this article.

\section{Funding}

The author(s) received no financial support for the research, authorship, and/or publication of this article.

\section{Notes}

1. Around $80 \%$ of the respondents under the age of 20 are in $\mathrm{O}$ or $\mathrm{A}$ Level studies. Including them would lower class-degree association by 2-3 percentage points but the ethnic patterns are the same as reported in the text.

2. Analysis was also conducted using ordinal logit regression on more fine-grained educational categories, and the pattern is similar to that shown in Table 1 (results are available on request).

3. Another analysis was conducted pooling all ethnic minority groups together and with the class effects compared with those for white respondents. The effect sizes were significantly bigger for whites than for the second generation from Class IV to Class IIIb/VII.

4. A two-level linear growth model is used to estimate the life-course effects on unemployment and access to the salariat and to address issues of heterogeneity in the trajectories by time-constant and time-varying covariates. The model is specified as follows.

Level-1 model:

$$
y_{t i}=\beta_{0 i}+\beta_{1 i}\left(A g e_{t i}-\overline{\mathrm{A}} \cdot{ }_{i}\right)+\beta_{2 i}\left(A g e_{t i}-\overline{\mathrm{A}} \cdot{ }_{i}\right)^{2}+\varepsilon_{t i}
$$

Level-2 model:

Model for the intercept

$$
\beta_{0 i}=\gamma_{00}+\gamma_{01} \text { Ethnicity }_{i}+\gamma_{02} \text { Generation }_{i}+\gamma_{03} \text { Region }_{i}+\mu_{0 i}
$$

Model for the linear rate of change

$$
\begin{aligned}
\beta_{1 i}= & \gamma_{10}+\gamma_{11}{\text { Marital } \text { status }_{i}+\gamma_{12} \text { Health }_{\text {condition }}+\gamma_{13} \text { Education }_{i}} \\
& +\gamma_{14} \text { Education }_{i} * \text { Ethnicity }_{i}+\mu_{1 i}
\end{aligned}
$$

where the outcome variable $\left(y_{t i}\right)$ pertains to people's labour market situation in terms of unemployment risks, defined as unemployment among the economically active $\left(\right.$ urate $\left._{t i}\right)$, or of access to the professional-managerial salariat (salariat ${ }_{t i}$ ). Both outcomes of interest are modelled as a function of age (centred respectively for men and women) and 
age-squared for individual $i$ at time $t$, controlling for time-invariant covariates of ethnicity, generational status and region, and time-varying covariates of marital status, health status, education, and education*ethnicity interaction. Additional analysis is conducted on the scarring effects of unemployment (previous wave's unemployment and cumulative unemployment histories up to the previous wave). The first model characterises individual growth trajectories with age, with $\beta_{0 i}, \beta_{1 i}$ and $\beta_{2 i}$ representing the intercept, the linear rate of change and the quadratic rate of change with age, respectively. Model 2 assesses inter-individual differences in change with age as associated with ethnicity, generational status and region, with the coefficients for the covariates denoted by $\gamma_{01}, \gamma_{02}$ and $\gamma_{03}$, respectively. Similarly, $\gamma_{11}$ to $\gamma_{14}$ are the coefficients for the time-varying covariates. The random within-individual error term, $\varepsilon_{t i}$, is assumed to be normally distributed, and the level 2 residual random errors, $\mu_{0 i}$ and $\mu_{1 i}$, are assumed to have a multivariate normal distribution.

5. The sample sizes for Bangladeshi men from age 20 to age 52 were fairly big, generally over 30 but the data for those over age 52 ought to be treated with caution.

6. Feliciano and Lanuza (2017) proposed a thesis of contextual attainment to account for the apparent paradox of second-generation educational achievement. As immigrants tend to be positively selected, they may have higher education than do their compatriots who stay in the country of origin. Therefore, second-generation achievement is mere class reproduction in keeping with parental pre-immigration educational position. My own view is that the thesis of contextual attainment as proposed by Feliciano and Lanuza and my own account in this paper is complementary. Perhaps my view has more explanatory power. Assuming a man from Mexico with primary level of education is working as a cleaner in the USA: he was in the top $20 \%$ in the educational hierarchy in Mexico. By comparison, only $2 \%$ of White Americans have primary education and the top $20 \%$ have at least some tertiary education (Feliciano and Lanuza, 2017: Figure 2). In such a case, would the Mexican man be more likely to ask his son to compete with his fellow students whose fathers were college-educated on the basis of the relative 'equal' position of the fathers? Or would he ask his son to aim higher, try harder and prepare more for possible barriers in the labour market? Perhaps 'both' is a more likely occurrence. It would be fascinating to conduct such a study in future. I am most grateful to an anonymous Reviewer and to the Editors for alerting me to this excellent paper.

\section{References}

Arulampalam W, Gregg P and Gregory M (2001) 'Unemployment Scarring'. The Economic Journal 111: F577-F584.

Bell D and Blanchflower D (2010) 'Youth Unemployment: Déjà Vu?' Stirling Economics Discussion Papers 2010-04. Available at: http://dspace.stir.ac.uk/bitstream/1893/2117/1/ SEDP-2010-04-Bell-Blanchflower\%5b1\%5d.pdf (accessed 1 September 2015).

Blau P and Duncan O with the collaboration of Tyree, A. (1967) The American Occupational Structure. New York: John Wiley \& Sons.

Blommaert L, Coenders M and Van Tubergen F (2014) Discrimination of Arabic-named applicants in the Netherlands: an internet-based field experiment examining different phases in online recruitment procedures'. Social Forces 92(3): 957-982.

Boliver V (2016) 'Exploring ethnic inequalities in admission to Russell Group universities'. Sociology 50(2): 247-266. 
Bourdieu P (1977) Cultural reproduction and social reproduction. In: Karabel J and Halsey AH (eds) Power and Ideology in Education. New York, NY: Oxford University Press, pp. 487-510. Bourdieu P (1984) Distinction: A Social Critique of the Judgment of Taste. Translated by Richard Nice. New York and London: Routledge, Taylor and Francis Group.

Bourdieu P (1986) The forms of capital. In: Lauder H, Brown P, Dillabough J and Halsey A (eds) Education, Globalization \& Social Change. Oxford: Oxford University Press, pp.105-118.

Bourdieu P and Passeron J-C (1977) Reproduction in education, society and culture. London: Sage.

Breen R and Goldthorpe J (1997) Explaining educational differentials: towards a formal rational action theory. Rationality and Society 9(3): 275-305.

Breen R, Luijkx R, Müller W, et al. (2010) Long-term trends in educational inequality in Europe: Class inequalities and gender differences. European Sociological Review 26: 31-48.

Cappelari L and Jenkins S (2007) Summarising multiple deprivation indicators. In: Jenkins $\mathrm{S}$ and Micklewright $\mathrm{J}$ (eds) Inequality and Poverty Re-Examined. Oxford: Oxford University Press, pp.166-184.

Coleman J (1988) Social capital in the creation of human capital. American Journal of Sociology 94: S95-S120.

Connor H, Tyers C, Modood T, et al. (2004) Why the Difference? A closer look at higher education minority ethnic students and graduates, Department of Education and Skills. Research Report 552.

Crawford C and Greaves E (2015) Socio-economic, ethnic and gender differences in HE participation. BIS Research Paper No.186, London: Department for Business, Innovation and Skills.

Devine F and Li Y (2013) The changing relationship between origins, education and destinations in the 1990s and 2000s. British Journal of Sociology of Education 34(5-6): 766-791.

Feliciano C and Lanuza Y (2017) An immigrant paradox? Contextual attainment and intergenerational educational mobility. American Sociological Review 82(1): 211-241.

Forstenlechner I and Al-Waqfi M (2010) A job interview for Mo, but none for Mohammed: religious discrimination against immigrants in Austria and Germany. Personnel Review 39(6): 767-784.

Goldthorpe J (2007) On Sociology. Stanford, CA: Stanford University Press.

Goldthorpe JH (2014) The role of education in intergenerational social mobility: problems from empirical research in sociology and some theoretical pointers from economics. Rationality and Society 26(3): 265-289.

Goldthorpe JH (2016) Social mobility in modern Britain: changing structure, constant process. Journal of the British Academy 4(1): 89-111.

Goldthorpe JH and McKnight A (2006) The economic basis of social class. In: Morgan S, Grusky D and Fields G (eds) Mobility and Inequality: Frontiers of Research in Sociology and Economics. California: Stanford University Press, pp.109-136.

Gugushvili A, Bukodi E and Goldthorpe JH (2017) The direct effect of social origins on social mobility chances: 'glass floors' and 'glass ceilings' in Britain'. European Sociological Review 33(2): 305-316.

Halsey A, Heath A and Ridge J (1980) Origins and Destinations: Family, Class, and Education in Modern Britain. Oxford: Clarendon Press.

Heath A, Li Y and Woerner-Powell $\mathrm{T}$ (forthcoming) Religion and poverty in the UK. Comparative Islamic Studies. 
Heath A and Li Y (2008) Period, life-cycle and generational effects on ethnic minority success in the labour market. Kölner Zeitschrift Für Soziologie Und Sozialpsychologie 48: $277-306$.

Heath A and Martin J (2013) Can religious affiliation explain 'ethnic' inequalities in the labour market? Ethnic and Racial Studies 36(6): 1005-1027.

Hout M (1988) More universalism, less structural mobility - the American occupational structure in the 1980s. American Journal of Sociology 93(6): 1358-1400.

Kao G and Tienda M (1995) Optimism and achievement: the educational performance of immigrant youth. Social Science Quarterly 76(1): 1-19.

Kao G and Thompson J (2003) Racial and ethnic stratification in educational achievement and attainment. Annual Review of Sociology 29: 417-442.

Khattab N (2009) Ethno-religious background as a determinant of educational and occupational attainment in Britain. Sociology 43(2): 304-322.

Khattab N and Modood T (2015) Both ethnic and religious: explaining employment penalties across 14 ethno-religious groups in the United Kingdom. Journal for the Scientific Study of Religion 54(3): 501-522.

Khattab N and Johnston R (2013) Ethnic and religious penalties in a changing British labour market from 2002 to 2010: the case of unemployment. Environment and Planning A 45(6): 1358-1371.

Lessard-Phillips L and Li Y (2017) Social stratification of education by ethnic minority groups over generations in the UK. Social Inclusion 5(1): 45-54.

Li Y (2015) 'Ethnic Minority Unemployment in Hard Times', Runnymede Perspectives: Aiming Higher Race, Inequality and Diversity in the Academy. London: Runnymede, pp.35-37.

Li Y (2017, forthcoming) Unequal returns: higher education and access to the salariat by ethnic groups in the UK. In: Arday J (ed.) Race and higher education. London: Palgrave MacMillan.

Li Y and Heath A (2008) Ethnic minority men in British labour market (1972-2005). International Journal of Sociology and Social Policy 28(5/6): 231-244.

Li Y and Heath A (2010) Struggling onto the ladder, climbing the rungs: employment status and class position by minority ethnic groups in Britain (1972-2005). In: Stillwell J, Norman P, Thomas C and Surridge P (eds) Population, employment, health and wellbeing. London: Springer, pp.83-97.

Li Y and Heath A (2016) Class matters: a study of minority and majority social mobility in Britain, 1982-2011. American Journal of Sociology 122(1): 162-200.

Li Y and Heath A (2017) Persisting disadvantages: a study of labour market dynamics of ethnic unemployment and earnings in the UK (2009-2015). Presentation at RC28, Seoul, May 2018.

Lin N (1990) Social resources and social mobility: a structural theory of status attainment. In: Breiger RL (ed.) Social Mobility and Social Structure. New York: Cambridge University Press, pp.247-271.

Lucas S (2001) Effectively maintained inequality: education transitions, track mobility, and social background effects. American Journal of Sociology 106: 1642-1690.

May T (2017) Prime Minister launches world-leading project on impact of ethnicity on everyday life. Available at: https://www.gov.uk/government/news/prime-ministerlaunches-world-leading-project-on-impact-of-ethnicity-on-everyday-life (accessed 12 October 2017). 
Modood T (2004) Capitals, ethnic identity and educational qualifications. Cultural Trends 13(2): 87-105.

Platt L (2011) Inequality within ethnic groups, the Joseph Rowntree Foundation. Available at: www.jrf.org.uk/publications

Portes A and Zhou M (1993) The new second generation: segmented assimilation and its variants among post-1965 immigrant youth. Annals of the American Academy of Political and Social Science 530: 74-96.

Portes A, Fernandez-Kelly P and Haller W (2009) The adaptation of the immigrant second generation: theoretical overview and recent evidence. Journal of Ethnic and Migration Studies 35(7): 1077-1104.

Raftery A and Hout M (1993) Maximally maintained inequality: expansion, reform, and opportunity in Irish education: 1921-75. Sociology of Education 66(1): 41-62.

Shah B, Dwyer C and Modood T (2010) Explaining educational achievement and career aspirations among young British Pakistanis: mobilizing "ethnic capital"? Sociology 44(6): 1109-1127.

Shavit Y and Blossfeld H-P (eds.) (1993) Persistent Inequality: Changing Educational Attainment in Thirteen Countries. Boulder, CO: Westview Press.

Shavit Y, Arum R and Gamoran A (eds) (2007) Stratification in Higher Education. Standford: Stanford University Press.

Spence M (1973) Job market signalling. Quarterly Journal of Economics 87(3): 355-374.

Treiman D (1970) Industrialization and social stratification. Sociological Inquiry 40(2): 207-234.

University of Essex. Institute for Social and Economic Research, NatCen Social Research, Kantar Public. (2016). Understanding Society: Waves 1-6, 2009-2015. [data collection]. 8th ed. UK Data Service. SN: 6614. Available at: http://doi.org/10.5255/UKDA-SN6614-9.

Waters M, Tran V, Kasinitz P, et al. (2010) Segmented assimilation revisited: types of acculturation and socioeconomic mobility in young adulthood. Ethnic and Racial Studies 33(7): 1168-1193.

Weiss A (1995) Human capital vs. signalling explanations of wages. Journal of Economic Perspectives 9: 133-154.

Wood M, Hales J, Purdon S, et al. (2009) 'A test for racial discrimination in recruitment practice in British cities', DWP Research Report 607. 